\title{
Kendali Posisi Linear Actuator Berbasis PID Menggunakan PLC
}

\author{
Randy Hardiansyah ${ }^{1}$, M. Syafei Gozali ${ }^{2}$, and Handri Toar ${ }^{3 *}$ \\ ${ }^{1}$ Politeknik Negeri Batam, Batam, Indonesia
}

*Email: randyhardiansyah23@gmail.com, syafei@polibatam.ac.id, toar@ polibatam.ac.id

\begin{abstract}
Abstrak-Linear actuator pada pneumatik mempunyai kemampuan gerak linier yang cepat, namun tidak diimbangi dengan kemampuan untuk berhenti pada setiap posisi pergerakannya. Pergerakan linear actuator pada umumnya hanya dapat berhenti pada kedua ujung terminalnya (endpoint). Sehingga diperlukan sistem kendali pergerakan posisi linear actuator. Dalam penelitian ini, penulis melakukan penelitian bagaimana merancang sistem kendali untuk mengendalikan posisi linear actuator. Pada penelitian ini menggunakan sistem kendali PID dengan metode trial and error dalam menentukan nilai konstanta PID dan menggunakan kontroler berupa PLC. Dari hasil pengujian sistem kendali posisi linear actuator waktu yang dibutuhkan untuk mencapai steady state dari posisi $0 \mathrm{~cm}$ menuju $30 \mathrm{~cm}$ yaitu 2.079 second. Hasil dari pengujian sistem kendali posisi linear actuator menggunakan kontrol PID menghasilkan nilai steady state error yang cukup kecil yaitu selisih $1 \mathrm{~mm}$ antara posisi target dan posisi tujuan.
\end{abstract}

Kata Kunci: Kontrol posisi, PID, PLC, linear actuator, kontrol pneumatik.

\section{PENDAHULUAN}

Aktuator pneumatik menawarkan beberapa keuntungan untuk aplikasi-aplikasi di industri manufaktur, antara lain karena gerakannya yang cepat dan aktuator yang murah jika dibandingkan dengan jenis aktuator lainnya, seperti hidraulik atau motor listrik. Secara umum untuk gerak linier, aktuator dapat dikelompokan menjadi tiga kelompok, yaitu: aktuator linier pneumatik, aktuator linier hidraulik dan motor listrik linier. Masing-masing aktuator tersebut mempunyai kelebihan dan kekurangan. Kelebihan aktuator linier pneumatik yang menonjol, yaitu kemampuan gerak liniernya yang cepat, tidak diimbangi dengan kemampuan untuk berhenti pada setiap posisi pergerakannya. Pada umumnya gerakan aktuator pneumatik hanya dapat berhenti pada ujungnya (endpoint), sehingga diperlukan sistem kontrol agar dapat mengatur posisi pergerakan linear actuator.
Penelitian yang telah dilakukan sebelumnya terdapat sistem pengontrolan linear actuator dengan kendali $\mathrm{P}$ (Proportional) menggunakan mikrokontroler DT-Basic Mini System oleh Roche Alimin [1], diperoleh bahwa pengaturan pergerakan linear actuator dengan mengatur sinyal PWM pada katup 3/2 solenoid on/off dan menghasilkan steady state error yang cukup besar. Pada penelitian lain terdapat sistem pengontrolan aktuator pneumatik dengan kendali PID menggunakan PLC CP1L [2], penelitian ini menggunakan dua buah katup elektromagnetis untuk mengontrol pergerakan aktuator pneumatik.

\section{DASAR TEORI}

\section{A. Kontrol PID}

Salah satu metode kontrol yang umum digunakan adalah kontrol PID [7]. Masing-masing aksi kontrol ini mempunyai keunggulan-keunggulan tertentu, dimana aksi kontrol proporsional mempunyai keunggulan risetime yang cepat, aksi kontrol integral mempunyai keunggulan untuk memperkecil error, dan aksi kontrol derivative mempunyai keunggulan untuk memperkecil error atau meredam overshot/undershot [5].

\section{1) Kontrol Proporsional}

Keluaran sinyal kontrol proporsional berbanding lurus dengan sinyal kesalahan, dapat dikatakan kontrol proporsional merupakan perkalian antara konstanta proporsional dengan nilai error. Berikut persamaan matematis dari kontrol proporsional:

$$
\mathrm{u}(\mathrm{t})=\mathrm{Kp} \cdot \mathrm{e}(\mathrm{t})
$$

Gambar 1 menunjukan diagram blok kontrol proporsional bahwa error merupakan selisih antara besaran yang diatur dengan besaran sebenarnya yang mempengaruhi kontrol dalam menghasilkan keluaran yang diinginkan. Berikut diagram blok dari kontrol proporsional: 


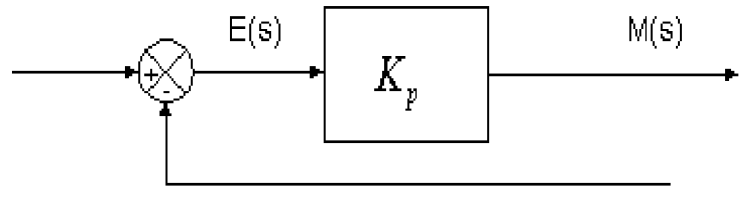

Gambar 1. Diagram Blok Kontrol Proporsional

\section{2) Kontrol Integral}

Keluaran sinyal kontrol integral berbanding lurus dengan penjumlahan sinyal kesalahan sebelumnya, dapat dikatakan kontrol integral merupakan perkalian antara konstanta integral dengan perubahan nilai error setiap waktunya. Berikut persamaan matematis dari kontrol integral:

$$
\mathrm{u}(\mathrm{t})=\mathrm{Ki} \cdot \int_{0}^{t} e(t) \cdot d t
$$

Gambar 2 menunjukan diagram blok hubungan antara error yang dihasilkan dengan keluaran sinyal kontrol integral, dengan adanya kontrol integral membantu menaikan respon sehingga menghasilkan keluaran yang diinginkan. Berikut diagram blok dari kontrol integral:

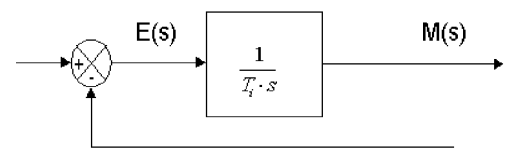

Gambar 2. Diagram Blok Kontrol Integral

\section{3) Kontrol Diferensial}

Keluaran sinyal kontrol diferensial berbanding lurus dengan penjumlahan sinyal kesalahan yang akan terjadi. Kontrol diferensial hanya akan berubah saat ada perubahan error sehingga apabila error bernilai statis maka kontrol tidak akan bereaksi. Berikut persamaan matematis dari kontrol diferensial:

$$
\mathrm{u}(\mathrm{t})=\mathrm{Kd} \cdot \frac{d e(t)}{d t}
$$

Gambar 3 menunjukan diagram blok control diferensial yang menggambarkan hubungan antara sinyal kesalahan dan keluaran sinyal kontrol yang dihasilkan pada sistem kontrol diferensial. Berikut diagram blok dari kontrol diferensial:

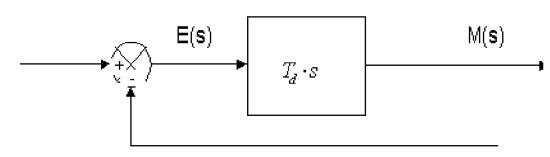

Gambar 3. Diagram Blok Kontrol Diferensial

\section{4) Kontrol Proporsional Integral Diferensial}

Kontrol PID merupakan gabungan antara kontrol P, I, dan D. Setiap kelebihan dan kekurangan dari masing-masing kontrol $\mathrm{P}$, I, dan $\mathrm{D}$ dapat saling menutupi dengan menggabungkan ketiganya secara paralel menjadi kontrol PID. Elemen-elemen kontrol P, I, dan D masing-masing secara keseluruhan bertujuan untuk mempercepat reaksi sebuah sistem, menghilangkan offset dan menghasilkan perubahan awal yang besar. Berikut persamaan matematis dari kontrol PID [10]:

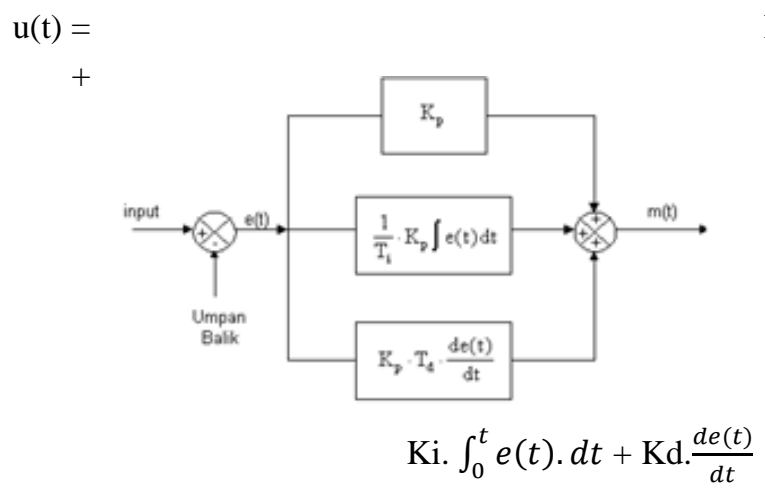

$\operatorname{Kp} . e(t)$

Gambar 4 menunjukan diagram blok control PID, karakteristik kontrol PID sangat dipengaruhi oleh kontribusi besar dari ketiga parameter P, I, dan D. Penyetelan konstanta $\mathrm{Kp}$, Ti, dan Td akan mengakibatkan penonjolan sifat dari masing-masing elemen. Satu atau dua dari ketiga konstanta tersebut dapat diatur lebih menonjol dibanding yang lain. Konstanta yang menonjol itulah yang akan memberikan pengaruh pada respon sistem secara keseluruhan.

\section{PERANCANGAN SISTEM}

\section{A. Diagram Blok Sistem Perangkat Keras}

Diagram blok sistem perangkat keras menunjukan rancangan keseluruhan yang bertujuan untuk mengontrol posisi linear actuator, hal tersebut tergambar dalam Gambar 5.

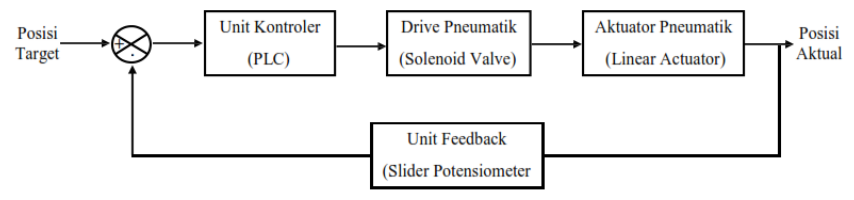

Gambar 5. Diagram Blok Sistem Perangkat Keras 
Gambar 5 merupakan rancangan yang digunakan dalam penelitian ini yang menggunakan sistem close loop. Dalam gambar tersebut terdapat posisi target yang hendak dicapai dalam sistem, kemudian data tersebut diolah oleh unit kontroler PLC dengan sistem kontrol PID. Sehinnga menghasilkan pergerakan linear actuator yang diatur melalui solenoid valve dan pembacaan posisi settiap pergerakan linear actuator oleh slider potentiometer sebagai unit umpan balik dalam sistem.

\section{1) Desain Slider Potentiometer}

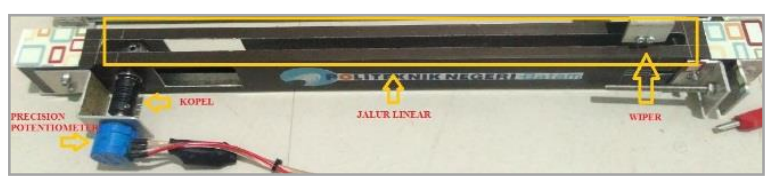

Gambar 6. Slider Potentiometer

Gambar 6 merupakan slider potentiometer yang telah dibuat berdasarkan perancangan sebelumnya. Sensor slider potentiometer menggunakan precision potentiometer yang dikopel dengan mekanik yang mampu bergerak sepanjang jalur linear. Precision potentiometer berputar $360^{\circ}$ sebanyak 10 kali putaran, dengan menghasilkan nilai resistansi $0 \Omega$ $100 \mathrm{k} \Omega$. Untuk mekanik yang mampu bergerak slider dibangun berdasarkan prinsip kerja konveyor terdiri dari belting yang bergerak diantara dua buah pulley, jarak antara dua pulley ditentukan sesuai dengan jarak tempuh aktuator (linear actuator).

\section{2) Desain Elektrikal Perangkat Keras}

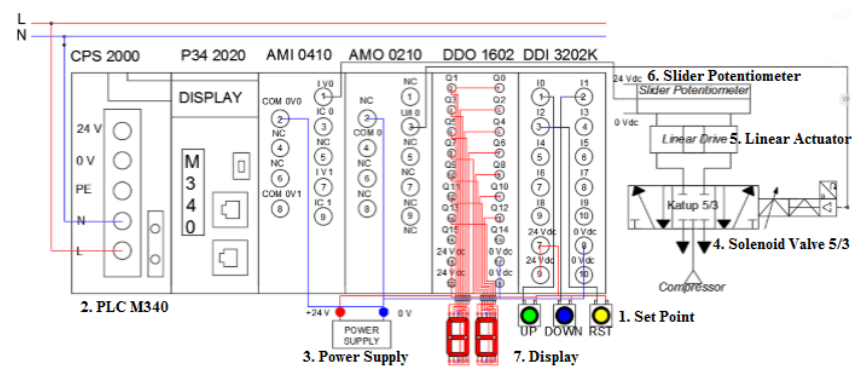

Gambar 7. Desain Elektrikal Sistem Perangkat Keras

Gambar 7 menunjukan desain elektrikal sistem perangkat keras. Sistem terdiri dari silinder pneumatik, katup kontrol arah proporsional MPYE 5/3, linear potentiometer, PLC, set point, dan tampilan set point. Silinder pneumatik menggunakan linear actuator dengan panjang stroke 300 milimeter, silinder pneumatik dengan karakteristik yang tidak diketahui digunakan untuk mengetahui apakah aktuator dapat dikontrol.

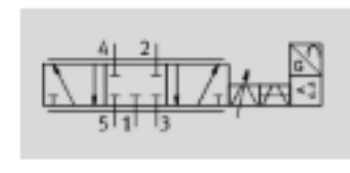

(a)

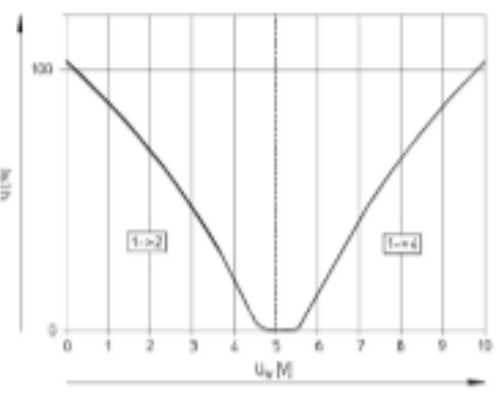

(b)

Gambar 8. (a) Katup Kontrol Arah Proporsional MPYE 5/3 dan (b) Grafik Respon Keluaran Katup Terhadap Masukan

Pada penelitian menggunakan katup kontrol arah proporsional MPYE 5/3, dikatakan proporsional karena hasil keluaran dari katup sebanding dengan nilai pada masukan katup tersebut. Masukan pada katup berupa tegangan analog 0 volt sampai 10 volt atau $4 \mathrm{~mA}$ sampai $20 \mathrm{~mA}$. Gambar 8 (b) menunjukan nilai keluaran katup (\%) berdasarkan nilai masukan pada katup. Saat masukan bernilai 0 volt maka keluaran katup akan membuka $100 \%$ dan tekanan udara akan bergerak dari port 1 menuju port 2 (Gambar 8(a)). Ketika masukan bernilai 5 volt maka keluaran katup tidak membuka sedikitpun, port 1 sebagai tempat masukan udara tersumbat. Kemudian jika masukan bernilai 10 volt maka keluaran katup akan membuka $100 \%$ namun tekanan udara melalui port 1 menuju port 4 (Gambar 8(a)) [8].

PLC M340 dengan modul analog input dan analog output digunakan dalam penelitian ini. Analog output mengatur keluaran PLC antara 0 volt sampai 10 volt yang masuk ke katup kontrol arah proporsional MPYE, bertujuan untuk mengatur tekanan udara yang dilewati katup menuju linear actuator. Analog output memiliki resolusi hingga $0.37 \mathrm{mV}$ dalam aplikasinya [9]. Untuk mengetahui dan memantau posisi linear actuator menggunakan analog input AMI 0410.

\section{B. Perancangan Perangkat Lunak}

Pada sistem kontrol linear actuator aplikasi atau perangkat lunak yang digunakan adalah unity pro xl. Pada program unity pro $\mathrm{xl}$ berisi program kontrol PID yang mampu mengontrol posisi linear actuator.

Gambar 9 menunjukan proses kerja dari sistem, dimulai dari start lalu melakukan inisialisasi awal dengan mengatur nilai $\mathrm{Kp}, \mathrm{Ki}, \mathrm{Kd}$, dan Ts. Kemudian menentukan nilai set point atau posisi target sebagai masukan pada sistem. Selanjutnya melakukan pembacaan posisi linear actuator menggunakan sensor slider potentiometer yang menghasilkan nilai posisi aktual dari aktuator. Nilai dari set point dibandingkan dengan nilai posisi aktual aktuator sehingga menghasilkan nilai error 
yang akan diolah unit kontroler menggunakan kontrol PID. Nilai output PID masuk ke katup analog 5/3 untuk mengerakan aktuator pneumatik. Pergerakan linear actuator dibaca oleh sensor slider potentiometer, pembacaan sensor feedback dibandingkan dengan set point hingga menghasilkan nilai error mendekati nol.

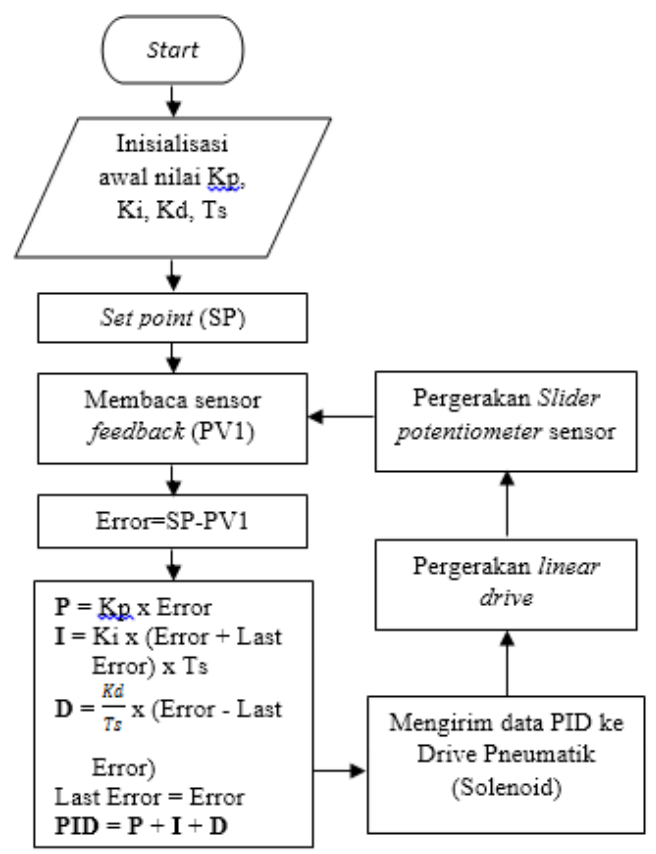

Gambar 9. Diagram Alir Sistem Perangkat Lunak

\section{PENGUJIAN DAN ANALISA}

Proses pengujian pertama adalah pengujian terhdap pembacaan yang dihasilkan oleh sensor slider potentiometer, hal ini untuk mengetahui nilai analog yang dihasilkan dan nantinya mengetahui nilai error dalam pembacaan posisi linear actuator.

\section{A. Pengujian Sensor Slider Potentiometer}

Dalam pengujian ini slider potensiometer bergerak per $1 \mathrm{~cm}$ dari posisi $0 \mathrm{~cm}$ sampai $30 \mathrm{~cm}$. Data hasil pembacaan setiap 1 $\mathrm{cm}$ dapat dilihat pada Tabel 1. Tabel 1 menunjukan hasil pengujian terhadap sensor slider potentiometer. Dapat simpulkan bahwa pergerakan slider potentiometer mampu menghasilkan data dan data yang dihasilkan bergerak linier antara posisi $(\mathrm{cm})$ dan data analog (int) slider potentiometer, hal ini dapat dlihat jika ditampilkan dalam bentuk grafik pada Gambar 10.
Tabel 1. Pengujian Sensor Slider Potentiometer

\begin{tabular}{|c|c|c|c|c|c|}
\hline $\begin{array}{c}\text { Posisi } \\
(\mathrm{cm})\end{array}$ & $\begin{array}{c}\text { Data } \\
\text { Analog } \\
\text { (int) }\end{array}$ & $\begin{array}{c}\text { Posisi } \\
(\mathrm{cm})\end{array}$ & $\begin{array}{c}\text { Data } \\
\text { Analog } \\
\text { (jnt) }\end{array}$ & $\begin{array}{c}\text { Posisi } \\
(\mathrm{cm})\end{array}$ & $\begin{array}{c}\text { Data } \\
\text { Analog } \\
\text { (int) }\end{array}$ \\
\hline 0 & 139 & 11 & 339 & 22 & 539 \\
\hline 1 & 156 & 12 & 357 & 23 & 557 \\
\hline 2 & 174 & 13 & 375 & 24 & 576 \\
\hline 3 & 192 & 14 & 394 & 25 & 592 \\
\hline 4 & 211 & 15 & 412 & 26 & 611 \\
\hline 5 & 228 & 16 & 430 & 27 & 628 \\
\hline 6 & 246 & 17 & 448 & 28 & 647 \\
\hline 7 & 266 & 18 & 466 & 29 & 664 \\
\hline 8 & 284 & 19 & 484 & 30 & 682 \\
\hline 9 & 302 & 20 & 503 & \multicolumn{2}{|c}{} \\
\cline { 1 - 2 } & 319 & 21 & 521 & &
\end{tabular}

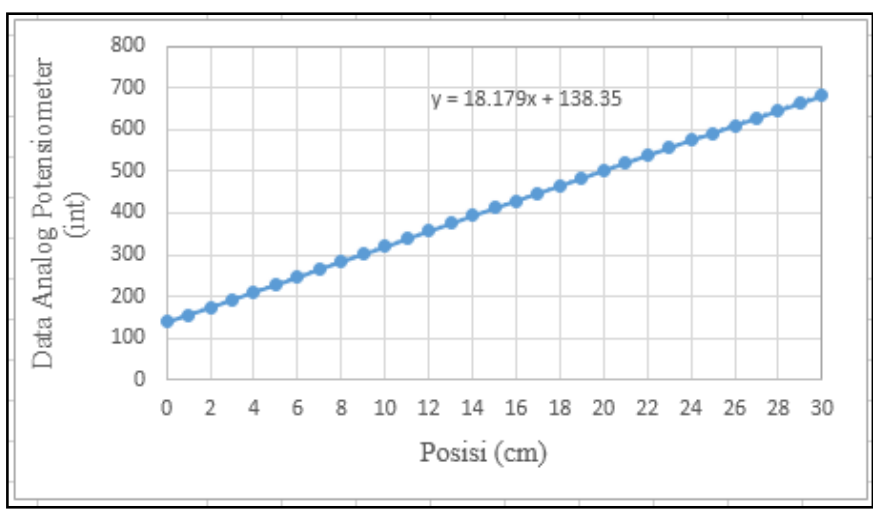

Gambar 10. Grafik Linieritas Posisi dan Data Analog Slide Potentiometer

Gambar 10 menunjukan nilai analog yang dihasilkan slider potentiometer bergerak linier dengan posisi dalam bentuk grafik, semakin besar nilai posisi maka nilai analog yang dihasilkan semakin besar pula. Pada grafik diatas terdapat persamaan garis yang dihasilkan yaitu:

$$
Y=(18.179 * x)+138.35
$$

Persamaan 4.1 digunakan untuk mengubah nilai posisi dari set point yang berbentuk. $Y$ adalah nilai analog yang dihasilkan dalam bentuk integer dan $\mathrm{x}$ adalah nilai posisi dari set point. digital menjadi nilai analog.

\section{B. Tuning PID}

Pengujian ini dilakukan untuk melihat hasil dari kontrol PID yang digunakan pada kendali posisi linear actuator. Metode yang digunakan dalam melakukan tuning konstanta PID adalah metode trial and error. Berikut gambar dari pengujian sistem kontrol PID dengan konstanta terbaik yaitu $\mathrm{Kp}=0.6$, 
$\mathrm{Ki}=0.1$, dan $\mathrm{Kd}=0.15$ pada posisi $0 \mathrm{~cm}$ ke $5 \mathrm{~cm}$ sampai 30 $\mathrm{cm}$ dengan selisih $5 \mathrm{~cm}$.

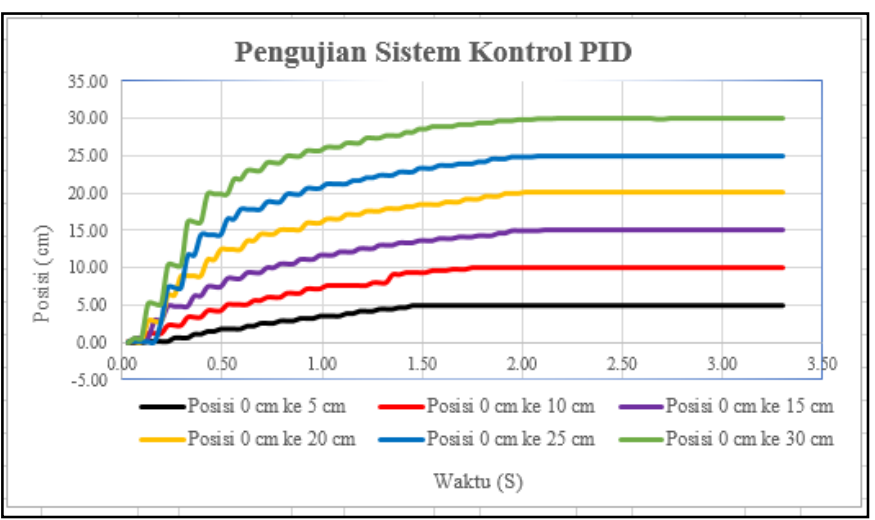

Gambar 11. Grafik Pengujian Sistem Kontrol PID

Gambar 11 menunjukan kinerja kontrol PID menggunakan $\mathrm{Kp}, \mathrm{Ki}$, dan Kd terbaik sehingga mampu bergerak maksimal menuju set point. Pada gambar tersebut nilai $\mathrm{Kp}, \mathrm{Ki}$, dan $\mathrm{Kd}$ didapatkan setelah melakukan tuning terhadap tiap-tiap konstanta dan memilih konstanta dengan steady state tercepat dan nilai yang stabil setelah mencapai steady state. Dari hasil pengujian yang telah dilakukan terhadap kontrol PID, terlihat kriteria sistem yang diinginkan hampir mendekati dan tanggapan sistem tidak memiliki overshoot. Pada pengujian posisi $0 \mathrm{~cm}$ ke $5 \mathrm{~cm}$, settling time terjadi pada waktu 1.45 second dengan nilai steady state error $0.04 \mathrm{~cm}$. Pengujian posisi $0 \mathrm{~cm}$ ke $10 \mathrm{~cm}$ menghasilkan settling time pada waktu 1.75 second dengan nilai steady state error $0.05 \mathrm{~cm}$. Pengujian posisi $0 \mathrm{~cm}$ ke $15 \mathrm{~cm}$ menghasilkan settling time pada waktu 2.112 second dengan nilai steady state error 0.05 $\mathrm{cm}$, namun waktu yang dibuthkan untuk mencapai steady state lebih lama dibandingkan dengan pengujian dari $0 \mathrm{~cm}$ ke 20 cm.. Pengujian posisi $0 \mathrm{~cm}$ ke $20 \mathrm{~cm}$ menghasilkan settling time pada waktu 2.013 second dengan nilai steady state error $0.01 \mathrm{~cm}$. Pengujian posisi $0 \mathrm{~cm}$ ke $25 \mathrm{~cm}$ menghasilkan settling time pada waktu 2.079 second dengan nilai steady state error $0.05 \mathrm{~cm}$. Pengujian posisi $0 \mathrm{~cm}$ ke $30 \mathrm{~cm}$ menghasilkan settling time pada waktu 2.079 second dengan nilai steady state error $0.02 \mathrm{~cm}$.

Berdasarkan Gambar 14 dapat dilihat bahwa nilai Kp 0.6 memiliki waktu steady state yaitu 7.326 second dan tidak ada overshoot. Pemberian nilai Kp 0.6 menghasilkan nilai yang tetap stabil setelah mencapai steady state. Pemberian nilai $\mathrm{Kp}$ yang terlalu kecil menyebabkan waktu steady state yang lama yaitu 8.514 second sehingga nilai Kp yang terlalu kecil tidak efektif digunakan. Pemberian nilai Kp yang terlalu besar menyebabkan sistem dengan nilai overshoot yang tinggi dan waktu steady state cepat, meskipun waktu steady state yang cepat namun menghasilkan nilai overshoot yang tinggi yaitu
$1.05 \mathrm{~cm}$, hal ini tentunya tidak cocok jika diaplikasikan dalam sebuah sistem yang menggunakan pergerakan silinder (linear actuator). Pemberian nilai $\mathrm{Kp}$ yang terlalu besar juga menghasilkan nilai yang tidak stabil setelah mencapai steady state yaitu nilai feedback masih mengalami perubahanperubahan kecil.

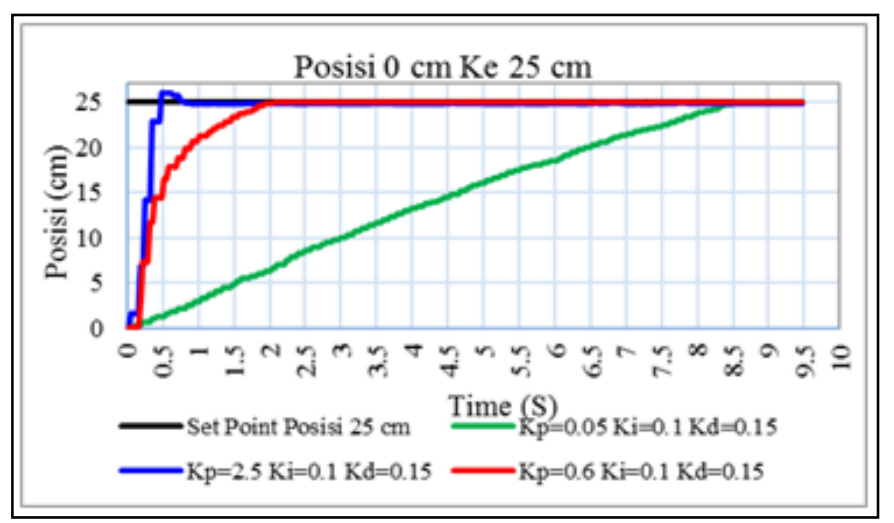

Gambar 12. Grafik Tuning Nilai Kp Pada PID Posisi $25 \mathrm{~cm}$

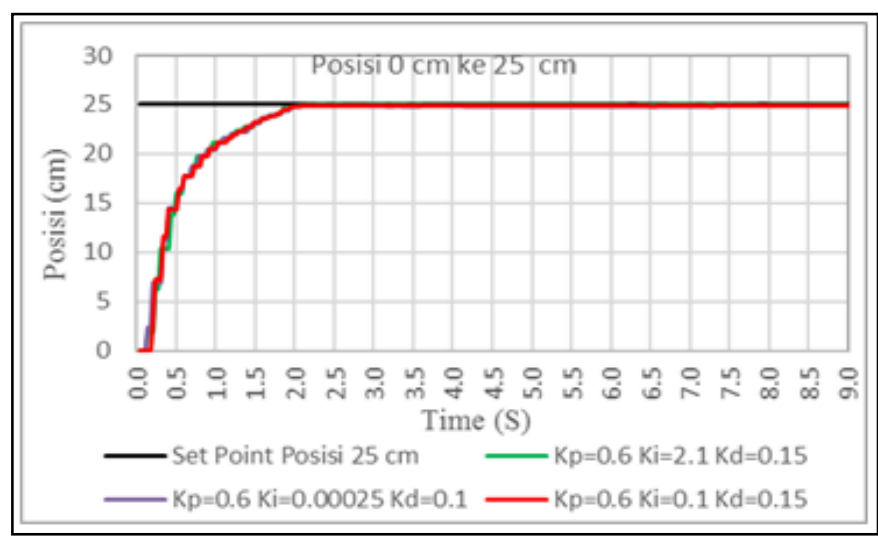

Gambar 13. Grafik Tuning Nilai Ki Pada PID Posisi $25 \mathrm{~cm}$

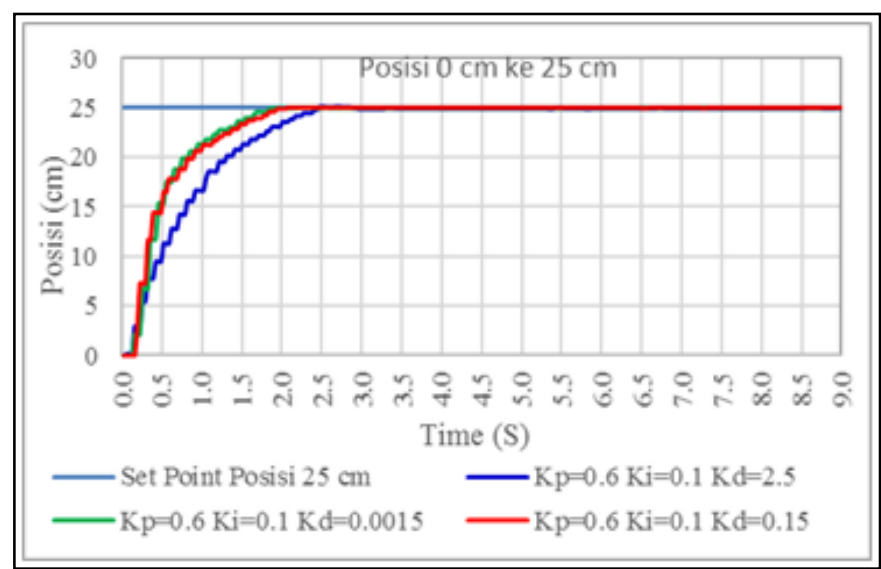

Gambar 14. Grafik Tuning Nilai Kd Pada PID Posisi $25 \mathrm{~cm}$

Pada Gambar 13 dapat dilihat bahwa tuning nilai Ki 0.1 memiliki nilai yang lebih stabil dibandingkan Ki 0.00025 dan 
Ki 2.1. Nilai Ki 0.1 memiliki waktu steady state pada waktu 2.08 second. Berdasarkan pengujian pada saat menggunakan Ki yang besar yaitu 2.1, maka menghasilkan sistem yang tidak stabil pada saat mencapai steady state masih terdapat gangguan pada sistem yang dihasilkan. Pemberian nilai $\mathrm{Ki}$ yang terlalu besar menghasilkan aktuator tidak berhenti secara keseluruhan, namun masih tampak sedikit pergerakan yang dihasilkan aktuator. Pemberian nilai Ki yang tepat mampu menghilangkan steady state error meskipun pengaruh kontrol integral terhadap sistem menghasilkan respon yang lebih lambat dibandingkan dengan kontrol proporsional. Sehingga pemilihan nilai Ki yang tepat menghasilkan nilai steady state error yang kecil.

Pada Gambar 13 dapat dilihat bahwa tuning nilai Kd 0.15 memiliki nilai yang lebih stabil setelah steady state dan settling time yang cukup cepat yaitu 2079 ms. Pemberian nilai $\mathrm{Kd}$ yang terlalu besar akan mengakibatkan sistem lebih lambat menuju waktu steady state dan pemberian nilai $\mathrm{Kd}$ yang terlalu kecil mengakibatkan sistem kurang stabil setelah mencapai steady state.kesimpulan

Berdasarkan hasil dan analisa dan pembahasan maka dapat disimpulkan sebagai berikut:

1. Sistem kendali dengan metode kontrol PID untuk mengontrol posisi linear actuator dengan menggunakan PLC dapat diterapkan.

2. Lama waktu yang dibutuhkan linear actuator untuk mencapai steady state dari posisi $0 \mathrm{~cm}$ menuju $30 \mathrm{~cm}$ yaitu 2.079 second.

3. Posisi dari linear actuator (posisi target) mendekati nilai set point yang diberikan dengan nilai error \pm 1 milimeter.

4. Telah mampu membuat sensor slider potentiometer untuk pembacaan posisi linear actuator.

\section{DAFTAR PUSTAKA}

[1] Alimin Roche. Kontrol Posisi Aktuator Pneumatik dengan Katup On/Off Secara PWM. Surabaya. 2007.

[2] S. Cajetinac, D. Seslija, S. Aleksandrov, M. Todorovic. PWM Control and Identification of Frequency Characteristics of a Pneumatic Actuator using PLC Controller. Kaunas: Technologija, 2012.

[3] Atika Wahyuningsih. "Sistem Pengepakan Produk Dengan Kendali PLC Siemens S7-300." Buku Tugas Akhir Sarjana I, Jurusan Teknik Elektro, Universitas Sanata Dharma, Yogyakarta, 2015.

[4] Diono."Monitoring dan Control Rumah Pintar Menggunakan Programmable Logic Control dan Pemrograman C\#”, Buku Tugas Akhir Diploma IV, Jurusan Teknik Elektro, Politeknik Negeri Batam, 2015.

[5] Guntur Wicaksono. "Kontrol PID Pada Robot Barelang 3.1", Buku Tugas Akhir Diploma III, Jurusan Teknik Elektro, Politeknik Negeri Batam, 2012.

[6] Sri Kusumadewi, “Artificial Intelligence (Teknik dan Aplikasinya) edisi pertama," Graha Ilmu : Jakarta, 2003.

[7] Ankita Nayak, Mahesh Singh. Study of Tuning of PID Controller by Using Particle Swarm Optimization. India, 2015.

[8] Proportional directional control valves MPYE, Festo.

[9] Modicon M340 With Unity Pro Analog Input/Output Modules User Manual. Schneider. 2012
[10] Udeh Tochukwu. Effect of PID Controller in Closed Loop Feedback System. 2014. 